\title{
Mapping of wind climate in urban environment
}

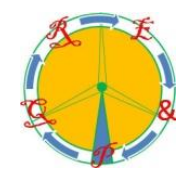

\author{
Dr. Péter Kádár, member of IEEE
}

Óbuda University

Dept. of Power Systems

Bécsi u. 94. Budapest H-1034 HUNGARY

Phone: +36 209447 241; fax: +30 1250 0940; e-mail: kadar.peter@kvk.uni-obuda.hu

\begin{abstract}
There are high expectations also in the urban areas for generating electricity by small scale wind turbines. In the inhabited city area of Budapest we made an experimental research for metering and modeling the wind climate of one of the buildings of Óbuda University. We had a wind meter-pair, one of them was used as a reference metering and we mapped the wind place-by-place. After the 10 times two weeks long metering periods we calculated the correlation of the reference point and the actual spot meterings.

For the validation of the metering we made a computer simulation, too. We arrived at the conclusion that metering and the simulation had a good correlation but in the urban area the wind course was really weak in the possible heights (approx. 10 meter above the buildings).
\end{abstract}

\section{Key words}

Small scale wind turbine, urban wind climate, wind map, wind metering, wind simulation

\section{Wind turbines in the city}

The wind turbine generated electricity is an option for the renewable and distributed generation [1]. The large scale rural applications are remarkable part of the power mix in several European countries as Denmark, Germany or Spain. A lot of small scale applications are offered but these are used only in rural areas in island mode remotely utilities' power networks. The different artistic small scale horizontal- and vertical axis wind turbines promise an alternative supply in the windy cities, too [2] [3] [4]. Is the urban application a real option?

In the laboratory we have two wind turbines. First is an AIR-X 400W Horizontal Axis Wind Turbine (HAWT) and a Sollight $1 \mathrm{KW}$ Vertical Axis Wind Turbine (VAWT - see Fig. 1.)

In this research we made an experimental research for metering and modeling the wind climate of one of the urban buildings of Óbuda University. The meterings were performed in the frame of students' project.
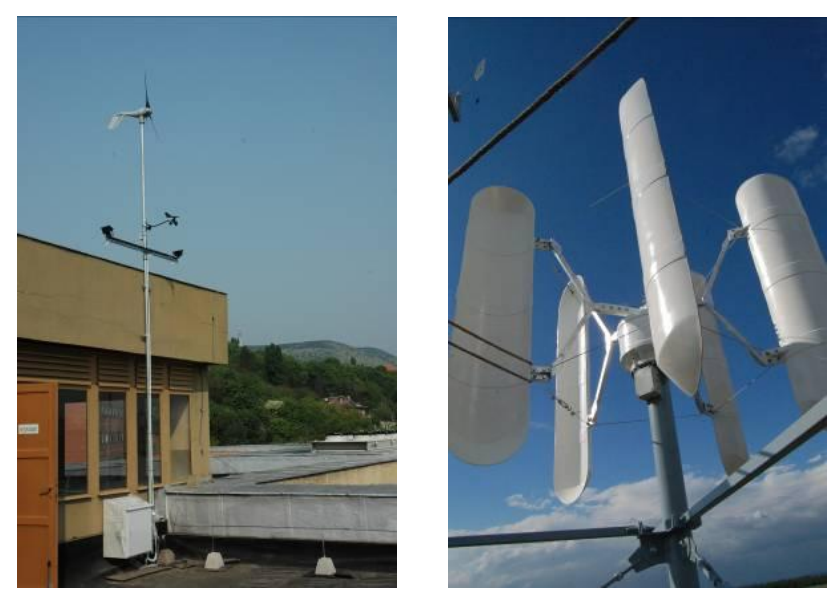

Fig. 1. HAWT and VAWT at Óbuda University

\section{Wind speed meterings}

The possible energy production can be estimated by the deeper knowledge of the local wind behaviour.

\section{A. Daily runs}

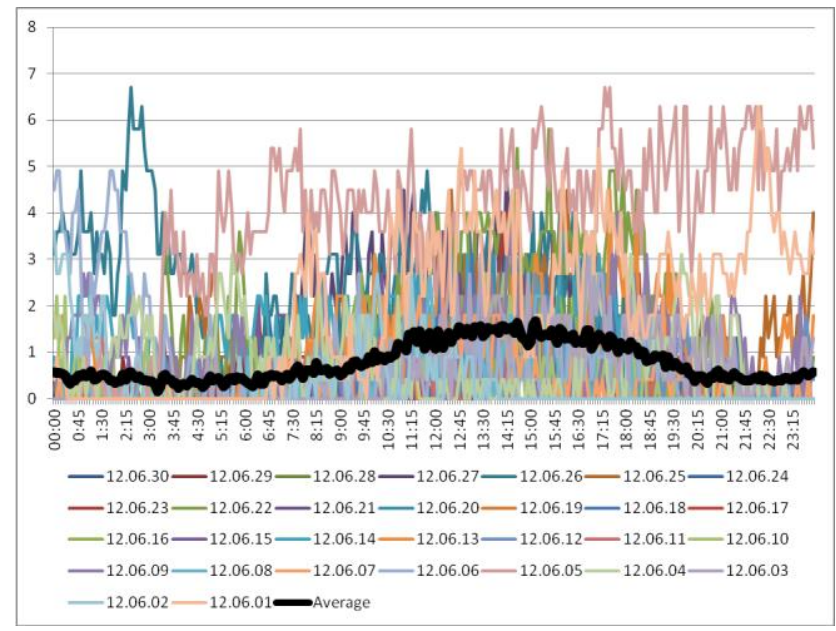

Fig. 2. Daily average wind speed in June 2012 by 5 min average measurements 
The simplest measurement is the daily speed runoff and the daily average course calculation for a longer time. Fig. 2. and 3. show the daily wind speeds in 5 min density in June at the reference metering point, and the average speed. On fig. 2 the average was calculated by $5 \mathrm{~min}$ average meterings (real average) on fig. 3. one can see the average of the peak speeds of every 5 minutes.

The typical wind turbine starts operation above $3 \mathrm{~m} / \mathrm{s}$ wind speed. Fig. 2. shows that the real average didn't hit the $3 \mathrm{~m} / \mathrm{s}$, so a lot of production can't be expected. Fig. 3 . shows that sometimes there are speeds above $3 \mathrm{~m} / \mathrm{s}$ so some production can be realized. The simple average metering is not applicable for the exact energy estimation.

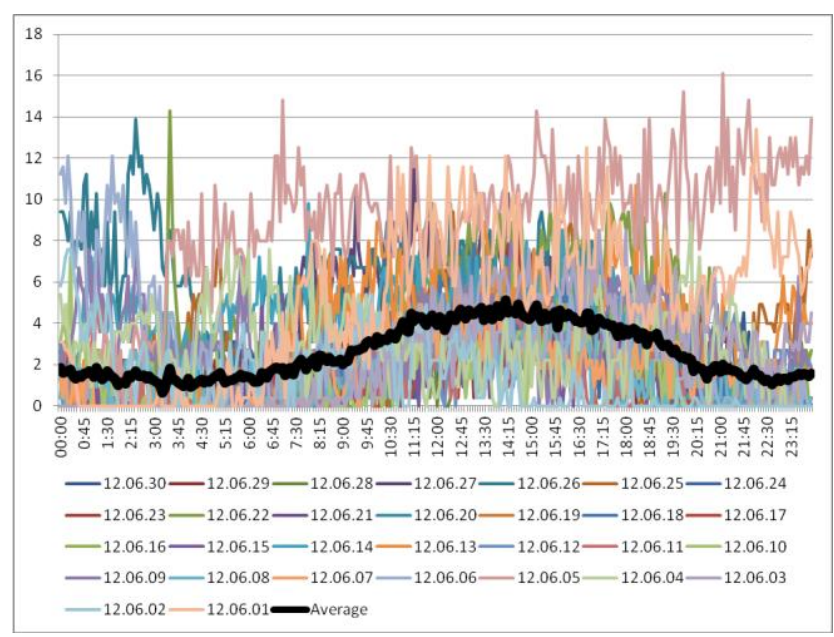

Fig. 3. Daily average wind speed in June 2012 by 5 min peak measurements

\section{B. Distribution}

The cumulative distribution function of the wind run of a longer period shows that how much measurements are above a limit. We can read from fig. 4 . that in 667 case the average speed hit the $3 \mathrm{~m} / \mathrm{s}$ meanwhile this limit is hit by the peak measurements more than 3000 cases (approx. 40 $\%$ of the measurements - so in these cases the turbines should start operation).

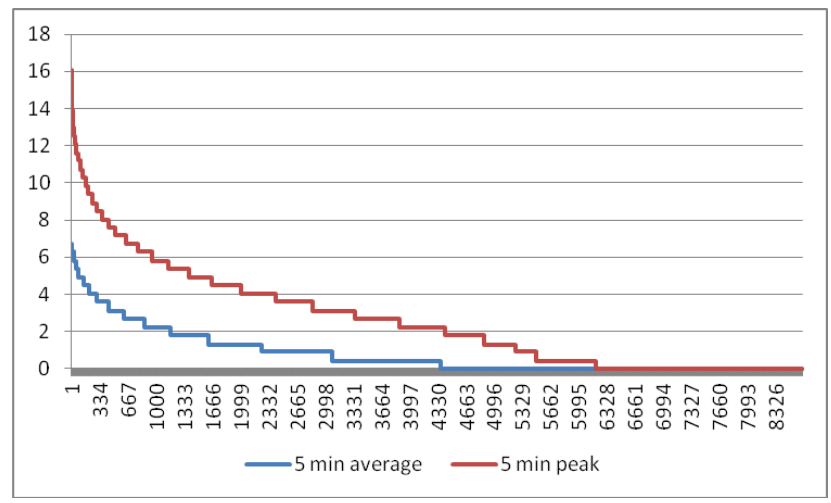

Fig. 4. Cumulative distribution function of the measurements

Knowing the factory operational curves of the turbines (output power in function of wind speed) the theoretical energy production can be calculated.
The local wind course never repeats itself, it is always unpredictable and unique. On the other side the behavior is well characterisable statistically, so it used to be described by a well and widely parameterable Weibull distribution function.

It is described by the Weibull distribution (see Eq.1.). In this form the ' $\lambda$ ' parameter refers to the shape of the curve, the ' $\beta$ ' parameter refers to the specific wind blow. ' $\beta$ ' is typically $1,12 * v_{\text {average speed of wind. This formalization }}$ helps us compare the energy production capability of the sites.

$f(x ; \alpha, \beta)= \begin{cases}\frac{\alpha}{\beta^{\alpha}} x^{\alpha-1} e^{-(x / \beta)^{\alpha}} & x \geq 0 \\ 0 & x<0\end{cases}$

\section{Eq.1. The Weibull distribution}

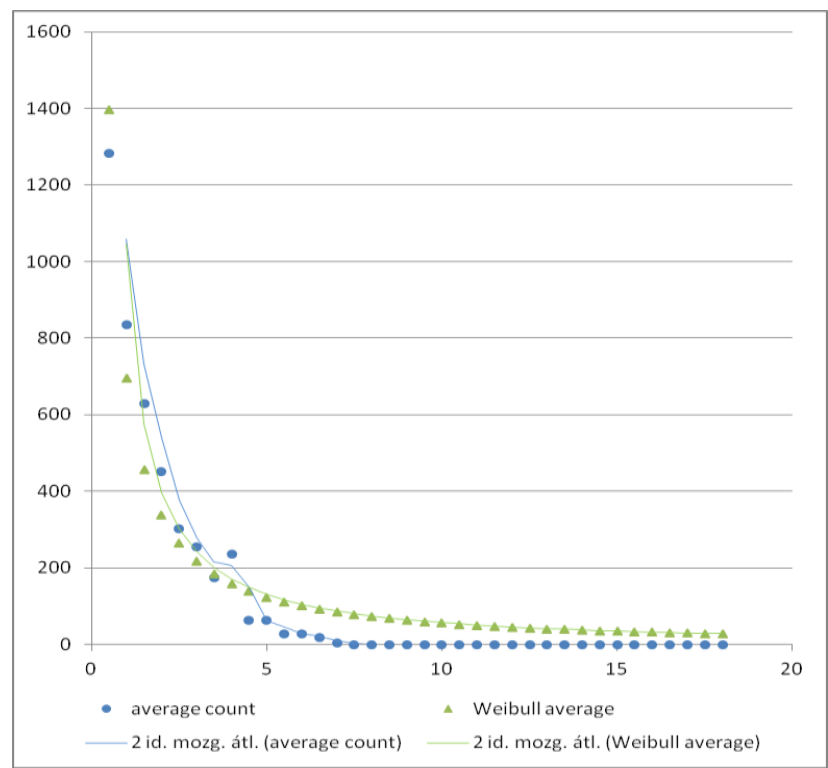

Fig. 5. Weibull distribution of the average wind speed

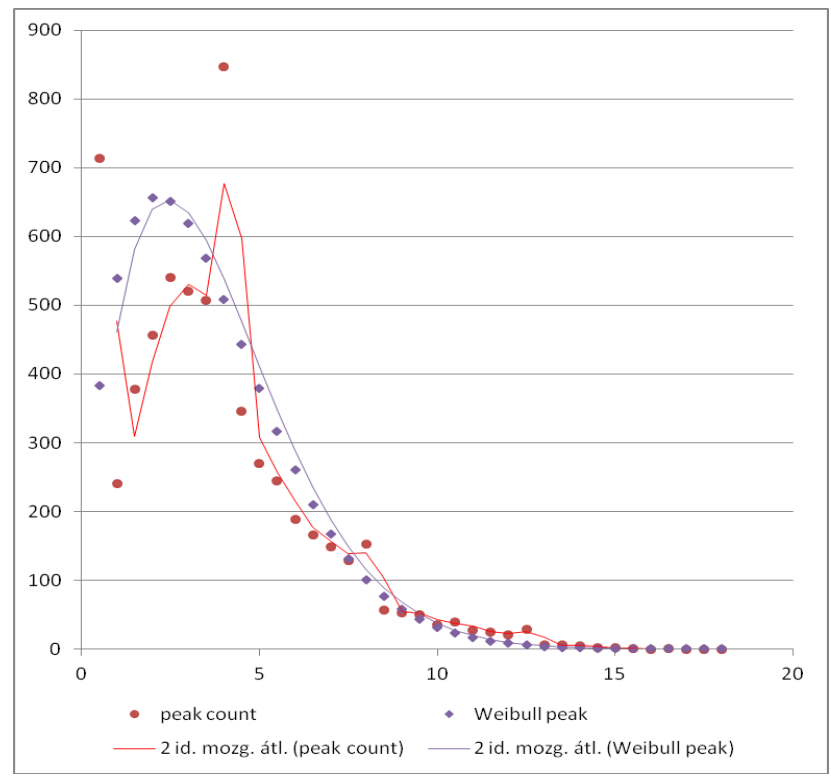

Fig. 6. Weibull distribution of the peak winds peed 


\section{Wind mapping}

We had a wind meter pair, one of them was used as a reference metering and we mapped the wind place-byplace. The UNITEK type meter collects the wind $\mathrm{max} / \mathrm{min} / \mathrm{average}$ and direction in every minute. As reference we used an AIR X - Davies WeatherLink meter (see Fig.7.). We made two week long metering sessions.

The basic idea of the metering is:

the wind course changes during the weeks, it is impossible to compare two remote meterings of two distinct time periods

- we work with a reference meter and with an "actual" spot meter. The external wind is obstacled or amplified by the local forms. The comparison of the spot metering and reference provides an "amplification" factor that is how large is the wind at a specific point of the building comparing to the reference point.

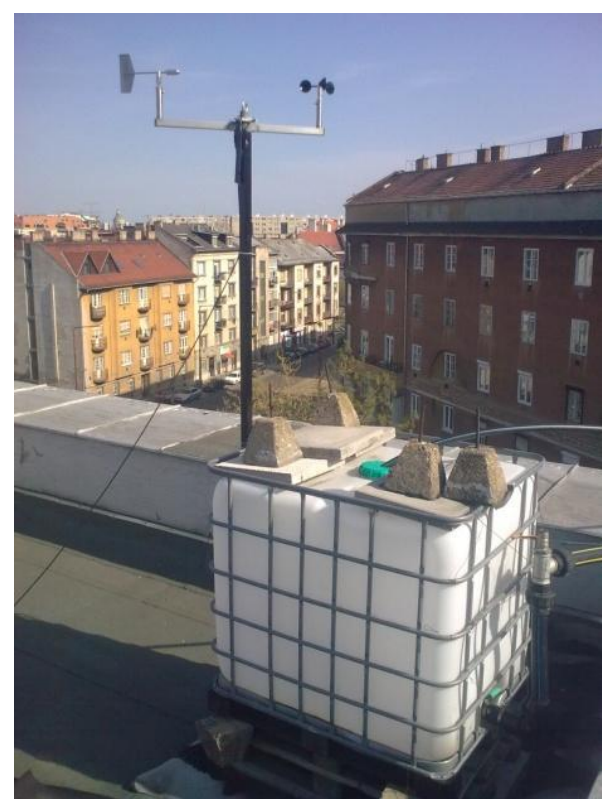

Fig. 7. UNITEK meter at metering point 3. "Water tank"

Ten metering series was done in the first half of year 2012. The following numbers were formed from the data:

- $\quad$ simple ratio of the average wind speed of the spot metering and the reference metering

- correlation of the wind speed of the spot metering and the reference metering in a specific speed range (speed filtering - 0-5; 5-10;10-15 and 15$20 \mathrm{~m} / \mathrm{s}$ ) [7]

- correlation of the wind speed of the spot metering and the reference metering in a specific direction range (direction filtering - eight direction quarters e.g. N-NE; NE-E, etc. N means North, E means East)

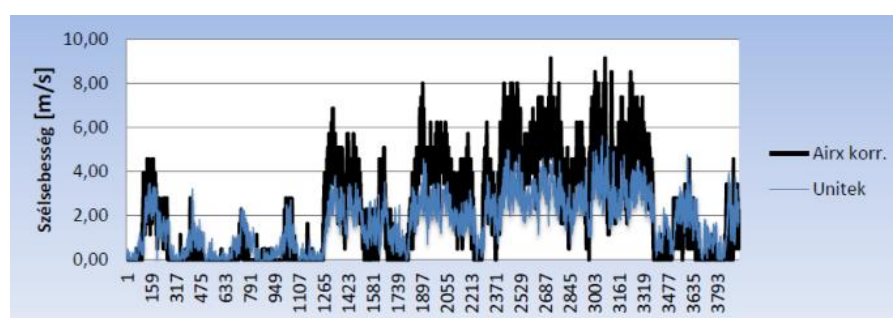

Fig. 8. "co-running" of the two measurements in real-time

Two parallel but distinct measurements can have differences because of

- $\quad$ unpunctuality of the meters

- inaccuracy of meters' internal clock

- local turbulences

- time delay due to the moving air in the space

Because of the above mentioned facts the "on-line" speed ratio calculation has large deviances. The better is to order it by amplitude before the ration calculation. This distributional reorganization results the cumulative distribution function of the wind speed(s). (Fig. 9. and 10.)

In an earlier research we found that for the micrositing of the turbines the best solution is to looking for the correlation between the reordered cumulative distributive functions instead of the correlation between the real-time measurements. [6] The basic idea is that the reordering do not disturb the energy production capability and provides "smother" correlation with less error $\left(\mathrm{R}^{2}\right)$.

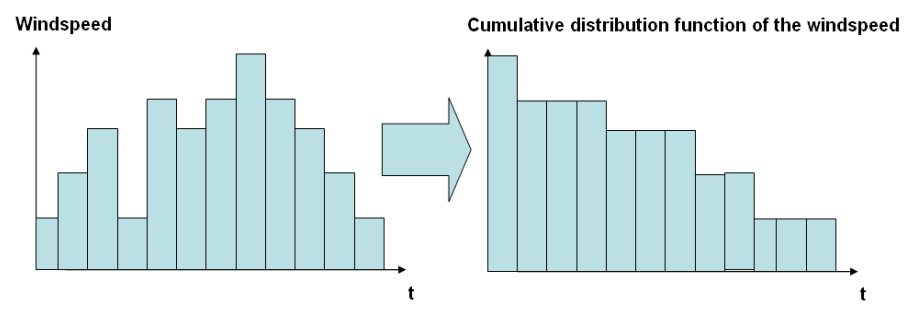

Fig. 9. Reorganisation of the wind measurements

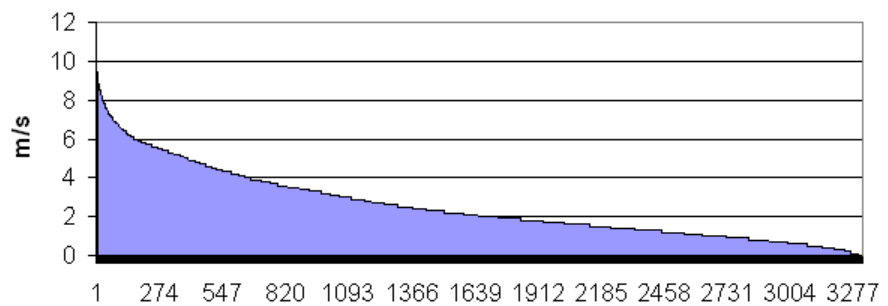

Fig. 10. Cumulative distribution function of wind measurements

We got the following results for measurement point 4.:

Ratio related to the reference point:

4653 / $5095=0,91$

that is "the wind in point 3 . is only 0,76 of the reference speed calculated on base of the average speed.

First we calibrated the two meters. 
Calculating the correlation we see a quite linear corunning (see next Fig. 11.). This correlation can be described by the function:

windspeed $_{\text {point } 4}=0,6793 *$ windspeed $_{\text {refpoint }}+0,11[\mathrm{~m} / \mathrm{s}]$

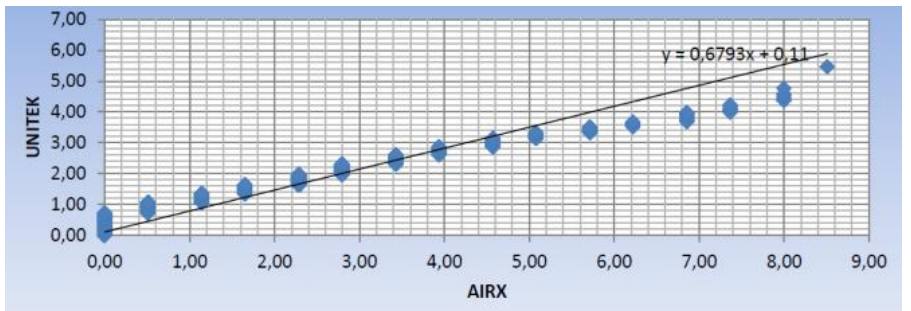

Fig. 11. Correlation of two measurements

Table I.: Summary of the measurement correlations

\begin{tabular}{|l|l|l|l|}
\hline $\begin{array}{l}\text { Meas. } \\
\text { no. }\end{array}$ & location & correlation & $\begin{array}{l}\text { ratio of } \\
\text { averages }\end{array}$ \\
\hline $\mathbf{1 .}$ & Reference point & $\mathrm{y}=0,930 \mathrm{x}-0,11$ & 1,35 \\
\hline $\mathbf{2 .}$ & Box-on-roof & $\mathrm{y}=0,934 \mathrm{x}-0,16$ & 1,11 \\
\hline $\mathbf{3 .}$ & Water tank & $\mathrm{y}=0,796 \mathrm{x}+0,53$ & 0,76 \\
\hline $\mathbf{4 .}$ & PV octogon holder & $\mathrm{y}=0,679 \mathrm{x}+0,11$ & 0,91 \\
\hline $\mathbf{5 .}$ & SE corner & $\mathrm{y}=1,180 \mathrm{x}-0,39$ & 1,39 \\
\hline $\mathbf{6 .}$ & NE corner & $\mathrm{y}=1,242 \mathrm{x}-0,36$ & 1,56 \\
\hline $\mathbf{7 .}$ & Chimney & $\mathrm{y}=1,749 \mathrm{x}-0,89$ & 2,44 \\
\hline $\mathbf{8 .}$ & N corner & $\mathrm{y}=0,832 \mathrm{x}+0,048$ & 0,97 \\
\hline $\mathbf{9 .}$ & NW corner & $\mathrm{y}=0,900 \mathrm{x}-0,27$ & 1,41 \\
\hline $\mathbf{1 0 .}$ & $\mathrm{W}$ corner & $\mathrm{y}=927 \mathrm{x}-0,20$ & 1,21 \\
\hline
\end{tabular}

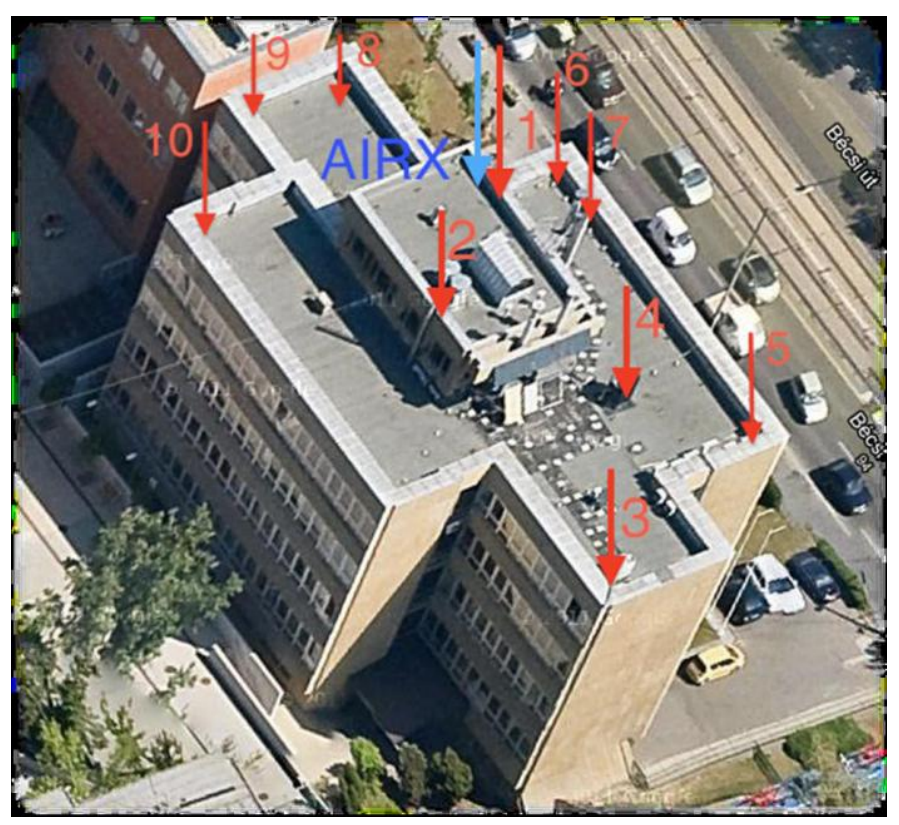

Fig. 12. Measurement points at the building roof

\section{Modeling}

We validated the measurements by computer simulation. First the metering building and the university campus environment were built in a 3D model. We used the Solid Works program [5]. After the construction we put the model into a virtual wind tunnel and we blew it from different directions and by different speed wind. We produced the artificial wind measurements and calculated the ratios metered earlier.

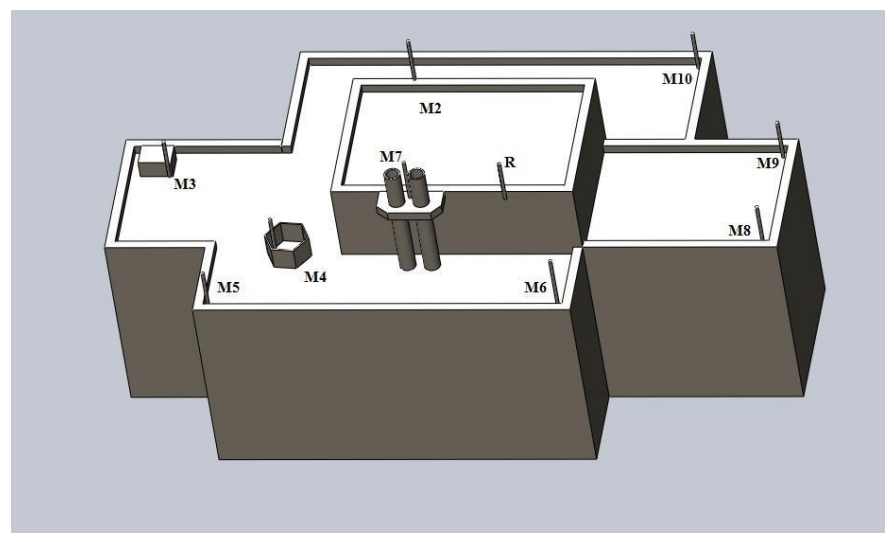

Fig.13. Model of the main building

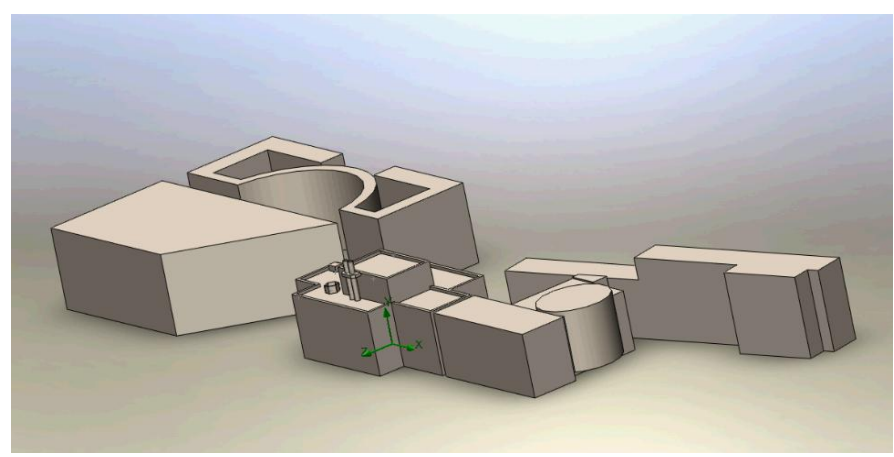

Fig. 14 Model of the university campus

The model was blown by the program. On the next figures the wind blow is visualized by fine and color threads (Fig. 15.) and "heat map" (Fig.16.).

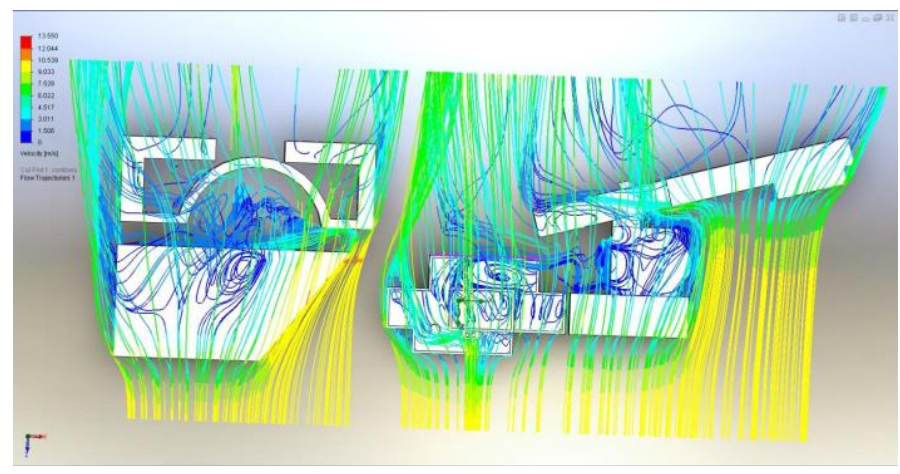

Fig. 15. Threads of the wind "flow" 


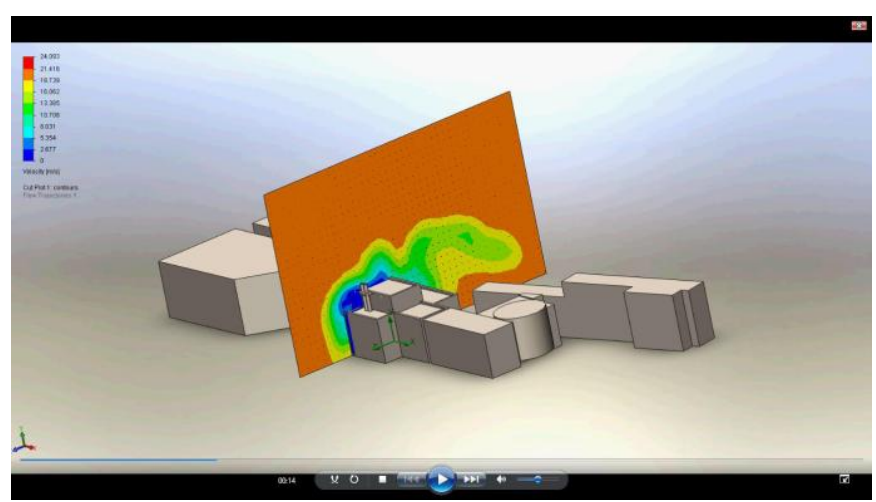

Fig. 16. Heat map of the wind "flow"

In the comparison table we used different wind speeds (5 $-10-15-20 \mathrm{~m} / \mathrm{s}$ ) and four wind directions (NE - SE SW - NW).

Table II. - Comparison of the simulation results with the measured ratios

\begin{tabular}{|c|c|c|c|c|c|c|}
\hline & M2 & M3 & M4 & M5 & M6 \\
\hline & & Villämháritó & Viztartaly & Napelem oktogon & 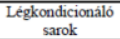 & $\begin{array}{c}\begin{array}{c}\text { Esszak- Keleti } \\
\text { sarok }\end{array} \\
\text { s. }\end{array}$ \\
\hline \multicolumn{2}{|c|}{ Méresia aränyscżàm } & $1.11 / 0.93$ & 0.76 & 0.91 & $1,39 / 1,17$ & $1.56 / 1,24$ \\
\hline \multirow[t]{5}{*}{$\begin{array}{l}\text { Szembol (E- } \\
\text { K) }\end{array}$} & & $\ldots$ & $\ldots$ & $\ldots$ & $\ldots$ & 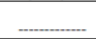 \\
\hline & $\begin{array}{l}5 \\
m / s\end{array}$ & $2: 4,5=0,44$ & $2,5: 4, .5=0,55$ & $3,5: 4,5=0,77$ & $3,8: 4,5=0,84$ & $3,2: 4,5=0,71$ \\
\hline & $\begin{array}{l}10 \\
\mathrm{~m} / \mathrm{s}\end{array}$ & $3: 4,5=0,66$ & $4,5: 7,5=0,6$ & $7: 7,5=0,93$ & $8: 7,5=1,066$ & $7,5: 7,5=1$ \\
\hline & $\begin{array}{l}15 \\
\mathrm{~m} / \mathrm{s}\end{array}$ & $4,5-9,1=0,49$ & $8: 11=0,72$ & $10: 13=0,76$ & $12: 13=0,92$ & $11: 13=0,846$ \\
\hline & $\begin{array}{l}20 \\
\mathrm{~m} / \mathrm{s}\end{array}$ & $6: 15=0,4$ & $15: 18=0,83$ & $13: 18=0,72$ & $16: 18=0,88$ & $15: 18=0,83$ \\
\hline \multirow[t]{5}{*}{ Balról (D-K) } & & $\ldots+\ldots+\ldots$ & $\ldots+\ldots$ & $\ldots$ & $\ldots+\ldots$ & $\ldots+\ldots$ \\
\hline & $\begin{array}{l}5 \\
\mathrm{~m} / \mathrm{s}\end{array}$ & $3,5: 3=1,16$ & $3,4: 3=1,13$ & $2,2: 3=0,73$ & $3: 3=1$ & $3: 3=1$ \\
\hline & $\begin{array}{l}10 \\
\mathrm{~m} / \mathrm{s}\end{array}$ & $6: 5=1,2$ & $4,5: 5=0,9$ & $3,2: 5=0,64$ & $6: 5=1,2$ & $4: 5=0,8$ \\
\hline & $\begin{array}{l}15 \\
\mathrm{~m} / \mathrm{s}\end{array}$ & $9: 7=1,28$ & $4: 7=0,57$ & $4,6: 7=0,65$ & $11,5: 7=1,64$ & $5,5: 7=0,78$ \\
\hline & $\begin{array}{l}20 \\
\mathrm{~m} / \mathrm{s}\end{array}$ & $9: 8=1,1$ & $12: 8=1,5$ & $7: 8=0,875$ & $6,5: 8=0,81$ & $6: 8=0,75$ \\
\hline \multirow{5}{*}{$\begin{array}{l}\text { Jobbrobl (E- } \\
\text { Ny) }\end{array}$} & & & 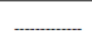 & ....... & $\ldots$ & \\
\hline & $\begin{array}{l}5 \\
\mathrm{~m} / \mathrm{s}\end{array}$ & $1,5: 2,8=0,53$ & $1,4: 2,8=0,5$ & $0,3: 2,8=0,11$ & $0,5: 2,8=0,18$ & $3: 2,8=1,07$ \\
\hline & \begin{tabular}{|l|l}
10 \\
$\mathrm{~m} / \mathrm{s}$
\end{tabular} & $2.65 .5=0.5$ & $2,7 \cdot 5,2=0.52$ & $1.35 .52=0.25$ & $1.35 .52=0.25$ & $2.7: 5.2=0.52$ \\
\hline & $\begin{array}{l}15 \\
\mathrm{~m} / \mathrm{s}\end{array}$ & $4: 6=0,67$ & $4.1: 6=0,68$ & $2: 6=0,33$ & $1.9: 6=0.32$ & $5.8: 6=0.97$ \\
\hline & $\begin{array}{l}20 \\
\mathrm{~m} / \mathrm{s}\end{array}$ & $5,3: 10=0,53$ & $5,4: 10=0,54$ & $1: 10=0,1$ & $1,8: 10=0,18$ & $9,1: 10=0,91$ \\
\hline Szimuláció á & tlaga & 0,74 & 0,75 & 0.57 & $\overline{0.7}$ & 0,84 \\
\hline
\end{tabular}

\section{Evaluation}

The objective of this work is to find the best place for the wind turbine placement. Comparing the measurement (ratios) and simulated values we got the following results:

Table III. - Summary of the measurement correlations

\begin{tabular}{|c|c|c|c|c|c|}
\hline \multicolumn{2}{|c|}{ Measurement - best sites } & \multicolumn{3}{c|}{ Simulation - best sites } \\
\hline 1 & M7 & Chimney & 1 & M7 & Chimney \\
\hline 2 & M6 & NE corner & 2 & M6 & NE corner \\
\hline 3 & M5 & SE corner & 3 & M3 & Water tank \\
\hline
\end{tabular}

\begin{tabular}{|c|c|c|c|c|c|}
\hline \multicolumn{3}{|c|}{ Measurement - worst sites } & \multicolumn{3}{|c|}{ Simulation - best sites } \\
\hline 1 & M3 & Water tank & 1 & M9 & NW corner \\
\hline 2 & M4 & PV octagonal holder & 2 & M4 & PV octagonal holder \\
\hline 3 & M8 & N corner & 3 & M8 & N corner \\
\hline
\end{tabular}

One can see the theory and practice meet well at the best and worst sites.

\section{Conclusion}

In this paper we described some wind course behaviour characterizing measurement mehodes: daily peak and average, monthly averages, distribution and Weibull mapping.

We made a measurement series for mapping the wind climate of an urban building. The measurements were validated by model simulation.

Although by both methods we find the best site, the long range wind meterings gave a relative low average wind speed and it means that we can't expect high energy production in this environment.

\section{Acknowledgement}

We thank students Imre Ress and Szilard Nagypal for the participation in the project for The project was supported by Óbuda University Power System Department.

\section{References}

[1] Eldridge Frank R., Wind Machines, 2nd Edition, Van Nostrand Reinhold Company, New York, U.S.A., 1980.

[2] Vertical Axis Wind Turbines: The History of DOE Program, U.S. Department of Energy, Sandia National Laboratories, U.S.A., 1998.

[3] Eggleston Eric, What Are Vertical-Axis Wind Turbines (VAWTs), American Wind Energy Association, Washington DC, U.S.A., 2001.

[4] John O. Dabiri: „Potential Order of Magnitude Enhancement of Wind Farm Power Density via Counter Rotating Vertical Axis Wind Turbine Array", Journal of Renewable and Sustainable Energy, Volume 3, Issue 4, July 19, 2011.

[5] www.solidworks.hu

[6] P. Kadar: Evaluation of Correlation the wind speed measurements and wind turbine characteristics; 8th International Symposium of Hungarian Researchers on Computational Intelligence and Informatics, CINTI 2007, 2007. nov. 15-17, Budapest, Hungary pp 429-440

[7] P. Kádár- L. Nagy: Wind measurement analysis for deployment urban small scale wind turbine; 10th International Symposium on Applied Machine Intelligence and Informatics (SAMI 2012) Herlany, Slovakia January 26-28, 2011 Paper 102 